\title{
Laparoscopic and hand-assisted cystorrhaphy strengthened with omental pedicle in dogs: Radiographic and ultrasonographic study
}

\author{
M.S. Alhamdany and L.M. Alkattan* \\ Department of Surgery and Theriogenology, Collage of Veterinary Medicine, University of Mosul, Mosul, Iraq \\ *laythalkattan@yahoo.com
}

(Received August 5, 2018; Accepted December 21, 2018)

\begin{abstract}
This study was designed to evaluate the using of two laparoscopic techniques for repairing an experimental cystotomy of urinary bladder reinforced with omental pedicle in dogs. Eighteen local breed male dogs were randomly allocated into two equal groups: first group an experimental cystotomy (about $2 \mathrm{~cm}$ ) was induced laparoscopically at the ventral surface of the urinary bladder, repaired with titanium clips and reinforced with the omental pedicle. In the second group: similar technique was followed; however, the induced was repaired with hand-assisted extracorporeal laparoscopic method. In both groups, several diagnostic parameters were followed including clinical / laparoscopic exploration, radiology, and ultrasonography. Results obtained in the first group shown the titanium clips 4-6 clips freely applicated and whole time consuming for performing operation was $45 \pm 2.1$ minutes. Clinically, the experimental animals didn't show any abnormal changes in their behavioral activities. Radiographic examination revealed distention of the urinary bladder accompanied by the presence of distances between the titanium clips; however, ultrasonography didn't show any leakage or thickness at the site of operation. Laparoscopic examination demonstrated mild adhesion between urinary bladder and adjacent organ. In the second group, the operation required $36 \pm 1.1$ minutes to be completed. Postoperatively, no signs of pain were observed, however, animals demonstrated post-operative transient hematuria, lasts for 24 hours, accompanied with severe adhesion between the bladder and abdominal wall. Radiographically, regular distention of the bladder was revealed, while ultrasonographic examination showed hyperechoic dots and thickening of the bladder wall. We concluded that the hand-assisted laparoscopic cystorrhaphy strengthened by omentum is a practical, time saving and mini-invasive surgical technique.
\end{abstract}

Keywords: Urinary bladder ruptures, Laparoscopy, Titanium, Omentum, Dog

Available online at http://www.vetmedmosul.com

$$
\begin{aligned}
& \text { إصلاح المثانة البولية بالجراحة المنظارية والجراحة المساعدة خارج الجسم وباستخدام سويقة الثرب }
\end{aligned}
$$

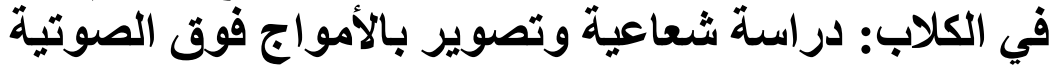

$$
\begin{aligned}
& \text { محمد صديق الحمداني و ليث محمود القطان } \\
& \text { فرع الجراحة و علم تناسل الحيوان، كلية الطب البيطري، جامعة الموصل، الموصل، العراق }
\end{aligned}
$$

صمدت الدراسه لتقييم استخدام تقنيتين في الجراحة المنظارية لإصلاح شق المثانة البولية بعد تدعيمها بسويقه الثرب في الكلاب. تضمنت التجربة ثمانية عشر كلبا محليا ومن الذكور و التي قسمت عشو ائيا إلى مجموعتين متساويتين. المجموعة الأولى يتم فئه فيها إحداث

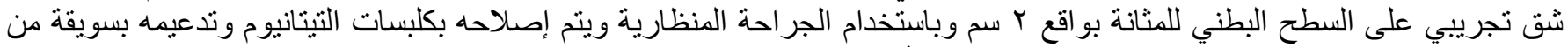

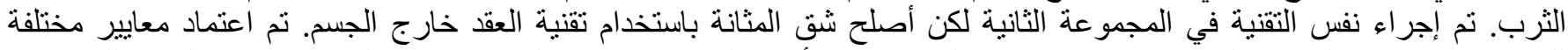

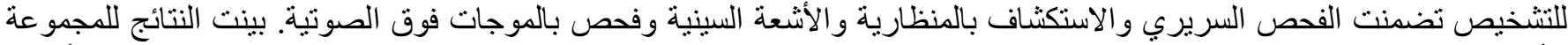

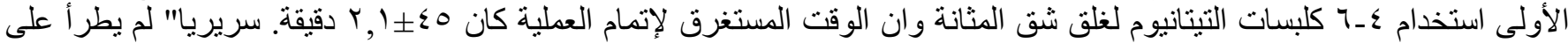
الحيو انات أبي تغيير ات في نشاطها. بينت نتائج فحص الأشعة انتفاخ المثانه وتباعد بين بكلبسات التيتانيوم وكذللك بينت نتائج فحص النيان السونار 


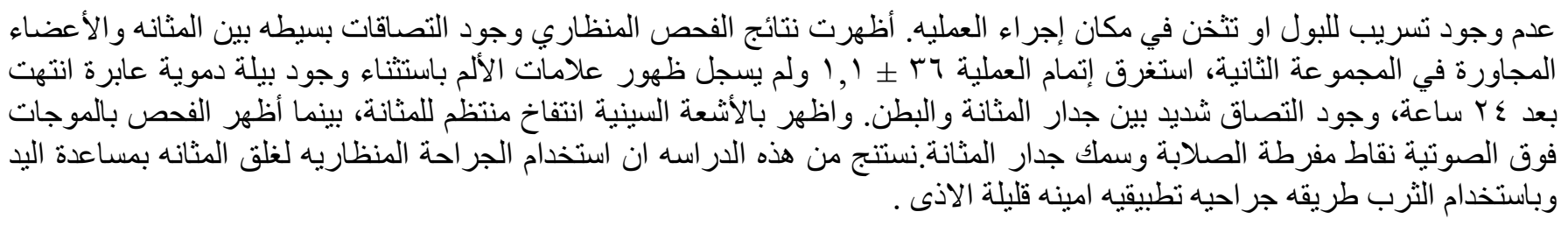

\section{Introduction}

Bladder rupture is a condition where the urinary bladder tears and releases urine into the abdominal cavity (1). Rupture may occur due to trauma, urinary obstruction, tumors, severe bladder disease, and during catheterization (2). A recent research pointed that traumatic urinary injuries are very important in small animals especially in dogs and cats which are considered to be popular affections and diagnosed by the using various methods, especially the positive contrast cystography (3). Cystorrhaphy is a surgical procedure, which is indicated for many purposes such as the reconstruction of the ruptured urinary bladder, removal of cystic/ urethral calculi, identification and biopsy of mass lesions, or treat urinary tract infection (4).

One of the most applicable indication of laparoscopy in veterinary medicine is the diagnosis of urinary bladder rupture $(5,6)$. Laparoscopy plays role in urology. Besides this, the hand-assisted technique has facilitated to adoption of laparoscopy (7). For instance, it has been used successfully in dogs to remove calculi from the bladder, where the bladder was exteriorized from one port and minilaparotomy (8), and for closure the cystotomy incision (9). The revascularizing properties of the greater omentum used as a vascular pedicle for the prefabrication of skin, to accelerate bone healing (10), and gastric repairing (11). Laparoscopic harvesting of the omentum was carried out for the first time by Saltz in 1993 in order to repair soft tissue defects in the knee in human (12). One of the most common applications of the omentum in veterinary medicine is placement of the omentum over sutured surgical sites in hollow organs such as the intestine or bladder. The omentum adheres to the incision site, which benefits from the omentum's pro-healing effects. Furthermore, omental adhesions prevent leakage of luminal contents through small gaps in the incision (12). The present study evaluated the beneficial effects of laparoscopic harvesting omentum to reinforce the experimentally defective urinary bladder, which was repaired with two different laparoscopic technique in dogs.

\section{Materials and methods}

Eighteen healthy male local stray dogs were included in the present study, aged 12-24 months and their weights were between $12-20 \mathrm{~kg}$. Animals were randomly allocated into two groups; for anesthesia, a mixture of Ketamine (Rotexmedica, Germany) / Xylazine (Interchemie, Holland), $15 \mathrm{mg}$ and $5 \mathrm{mg} / \mathrm{kg}$ BWt respectively (13) was given intramuscularly. In group one three ports were selected to introduce the laparoscopic instruments (KARL STORZ Endoscopy America, Inc, Germany) (Figure 1). The experiment approved by Collage of Veterinary Medicine University of Mosul. Pneumoperitoneum was successfully done with $\mathrm{CO}_{2}$ which was smoothly deliver into abdominal cavity at the pressure between $8-12 \mathrm{~mm} / \mathrm{Hg}$ in about $8 \mathrm{~L} / \mathrm{min}$ gas flow (14). The position of animals was at dorsal position and telescope introduced cranial to the umbilicus. The surgical protocol included evacuation of the urinary bladder by Foley catheter, and then a twocentimeter injury was made at the ventral surface of urinary bladder using laparoscopic scissors. The experimental injury was repaired by 4-6 titanium clips, and then the operation site was strengthened with the omental pedicle. In the second group, the dogs underwent the same manner of treatment except only two ports were used (Figure 2) and the bladder fixed to the abdominal wall, mini laparotomies were performed with aid of laparoscopic tools, to establish the experimental injury accessible for suturing, the adipose tissue and omentum were withdrawn and fixed directly to the site of operation for enfolding (Figure 3). The injury was sutured with Vircyl 3.0 (Ethicon) suture material. Postoperatively, all cases were subjected to clinical inspection and a routine laparoscopic revision of the organs was applied to determine both the position of the urinary bladder and the presence / absence of any leakage. In addition, radiological and ultrasonography (Real Time Ultrasound scanner, Zhou Kaixin Electronic Instrument, China) examinations were undertaken at different times 14 , 28,35 days after the operation.

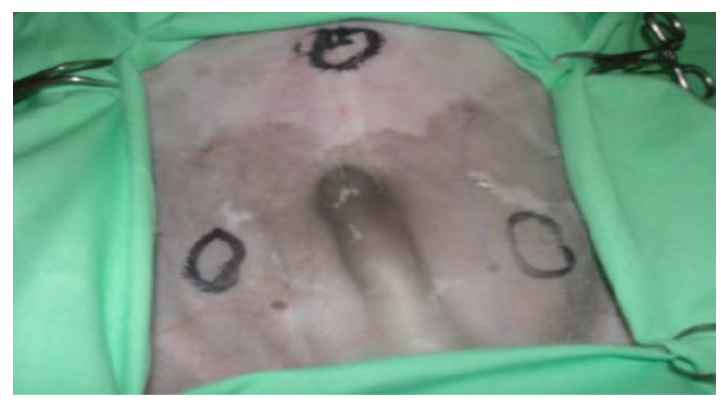

Figure 1: Ports of introducing instrument in first group. 


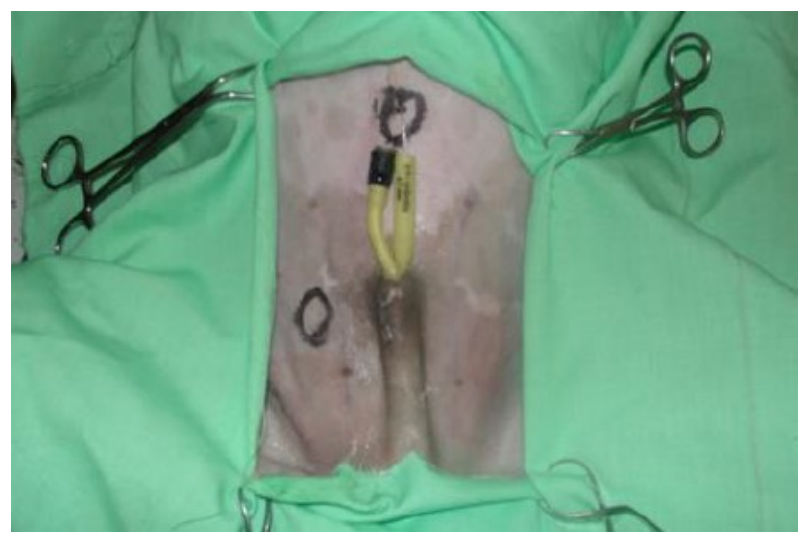

Figure 2: Ports of introducing instrument in second group.

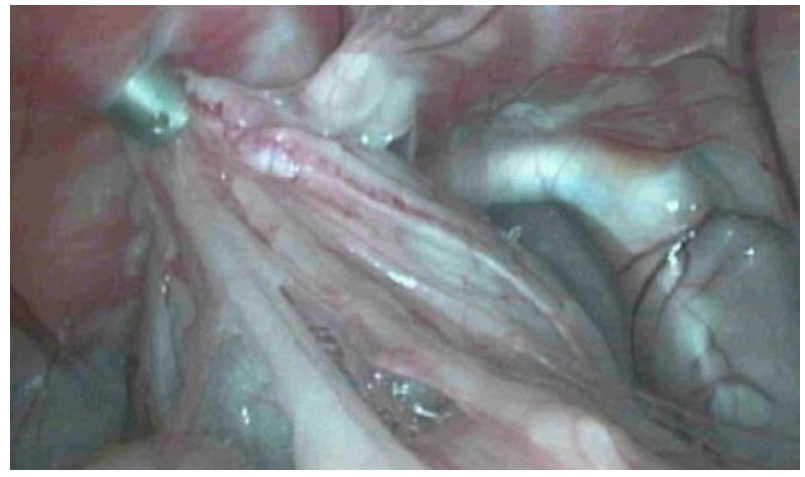

Figure 3: Adipose tissue and omentum were withdrawn and fixed directly to the site of operation for enfolding.

\section{Results}

Protocol of ketamine/ xylazine was sufficient to produce general anesthesia for laparoscopic and hand assisted cystorrhaphy in dogs. All animals were recovered from anesthesia without apnea or hypothermia. In the first group, the operation required a minimum of $45 \pm 2.1 \mathrm{~min}$ to be achieved with no adverse effects of the laparoscopic tools on the animal activity, except signs of pain and hematuria. These two signs were subsided and animals reacted and appeared healthy within two days postoperatively. During operation, mild complications were exhibited such as minor bleeding, which may obscure vision, and mild leakage of urine. Thirty-five days postoperatively, there was adhesion between urinary bladder and viscera (Figure 4). The radiographic examination revealed a regular shaped and distended urinary bladder, free from leakage with the presence of titanium clips at different distances (Figure 5,6). Similarly, on ultrasonographic examination, the wall of the urinary bladder appeared normal with no leakage; however, at the $14^{\text {th }}$ and $35^{\text {th }}$ days after the operation, moderate hyperechoic dots were noticed at the craniodorsal aspects of the urinary bladder (Figure 7, 8).

In the second group, the overall time required to achieve the operation was $36 \pm 1.1 \mathrm{~min}$, where no hematuria or signs of severe pain was revealed during of maturation. laparoscopic examination showed severe adhesion between the urinary bladder and omentum with abdominal wall at the site of exteriorizing omentum and urinary bladder, there was no leakage during different periods of laparoscopic examination (Figure 9). Radiographically, there was normal anatomical shape of urinary bladder (Figure 10). Ultrasonographic examination of the second group showed no leakage, however, thickness of the urinary bladder wall with hyperechoic dots were revealed after 14 and 30 days (Figure 11, 12).

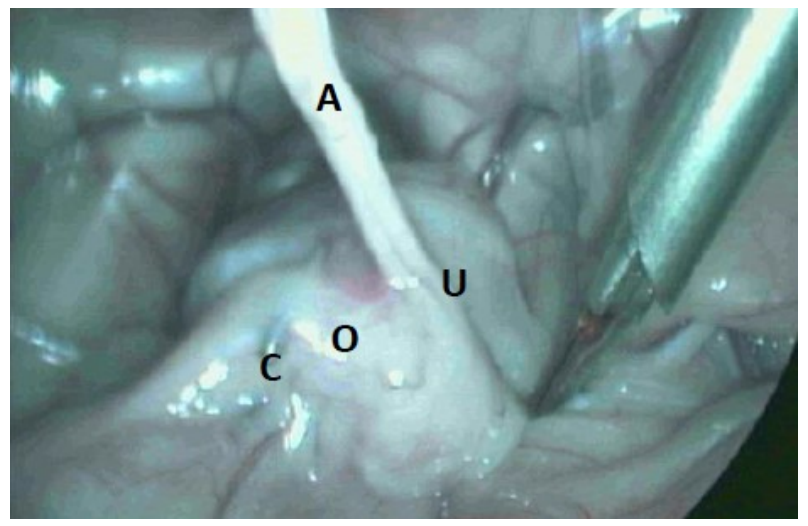

Figure 4: First group Treated dog 35 days post operatively (A) adhesion (C) titanium clips fix (O) omentum with urinary bladder $(\mathrm{U})$.

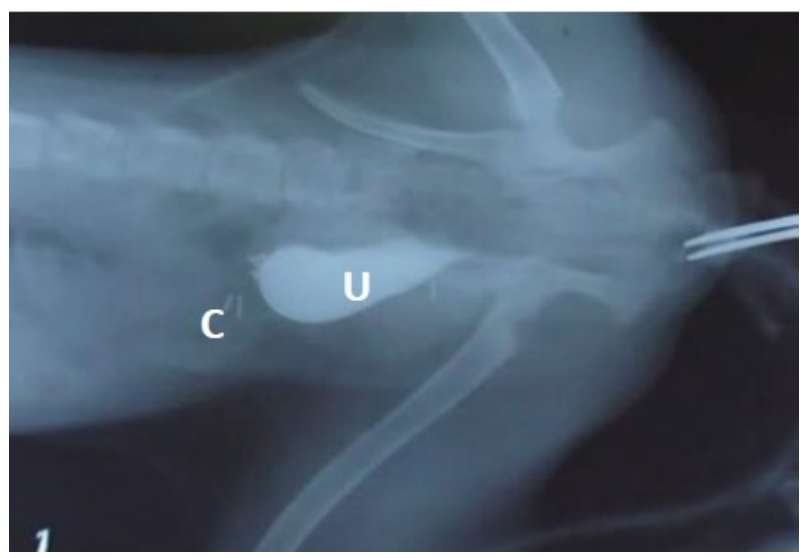

Figure 5: Radiographic image with ventromedial view by positive contrast $\mathrm{X}$ rays, at 14 days, shown the distended urinary bladder $(\mathrm{U})$, titanium clips $(\mathrm{C})$ fixed with different distances. 


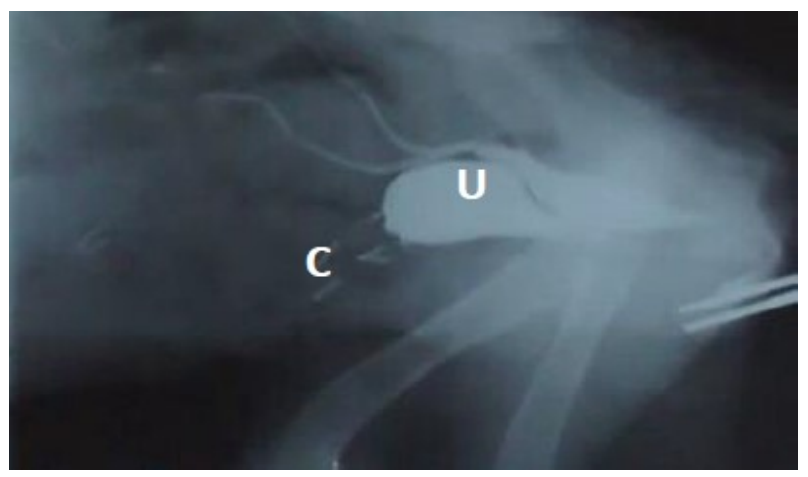

Figure 6: Radiographic image with lateral view by positive contrast $\mathrm{X}$ rays, at 28 days, shown the distended urinary bladder (U), titanium clips (C) fixed with different distances.

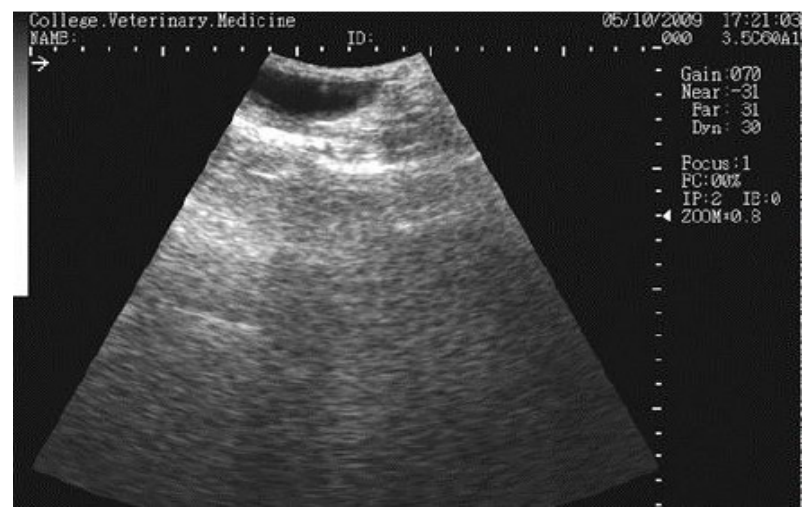

Figure 7: longitudinal plan of repaired bladder in first group 14 days postoperatively showing moderate hyperechoic dots indicting of craniodorsal wall of the urinary bladder, normal oval shape with no leakage.

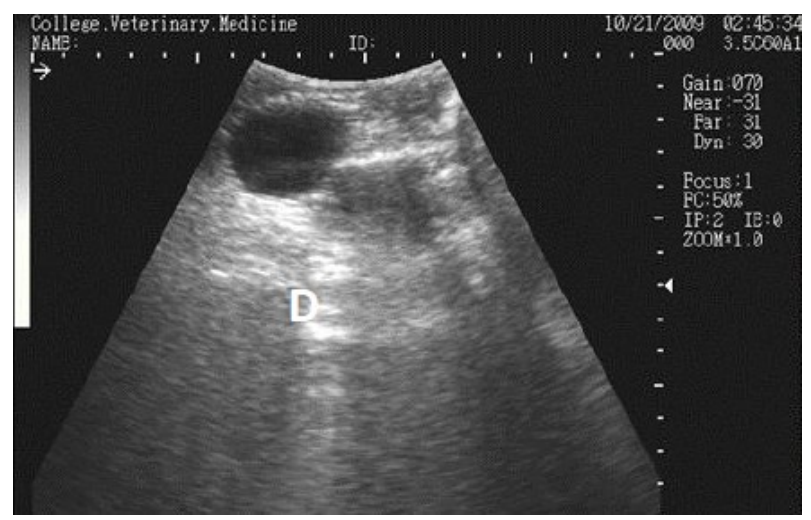

Figure 8: Longitudinal plan of repaired bladder in first group 35 days post operatively showing moderate hyperechoic dots (D) indicting of craniodorsal wall of the urinary bladder, normal shape with no leakage.

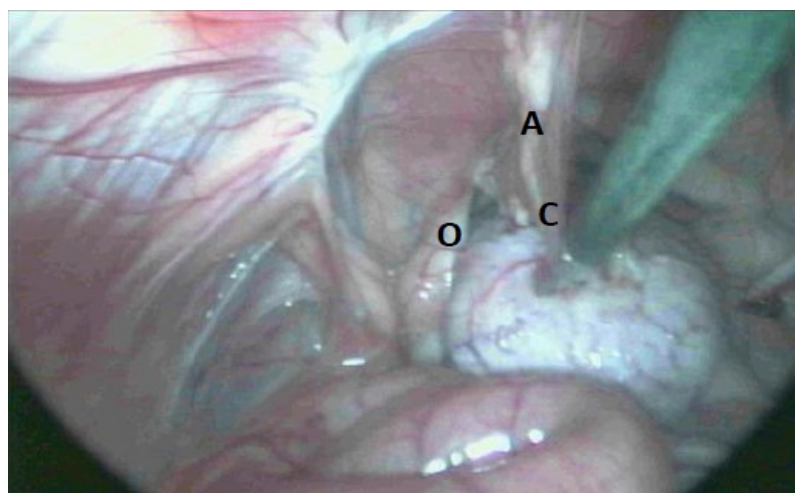

Figure 9: Second group treated $\operatorname{dog} 28$ days post operatively (A) adhesion (C) fix (O) omentum with distended urinary bladder (a) adhesion at the site of omentum harvesting.

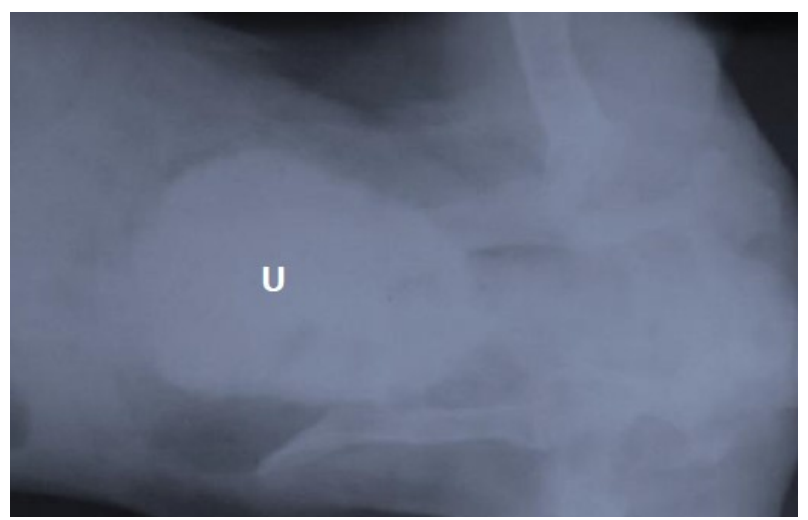

Figure 10: Radiographic image with lateral view by positive contrast $X$ rays, at 14 days, shown the distended urinary bladder $(\mathrm{U})$ in the second group.

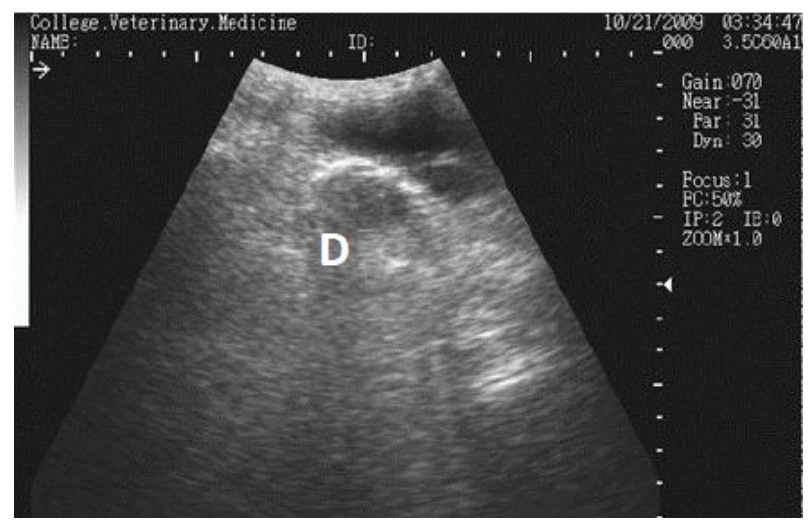

Figure 11: Longitudinal plan of repaired bladder for the second group after 14 days showing mild hyperechoic dots (D) indicting of craniodorsal wall of the urinary bladder, with irregular shape. 


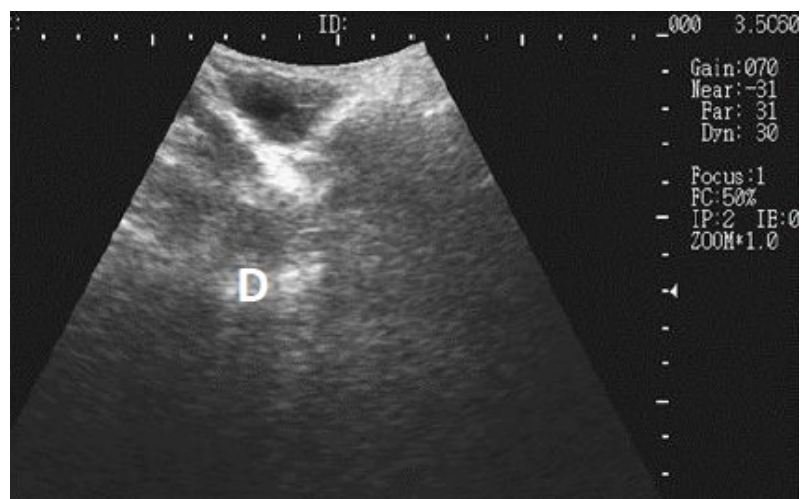

Figure 12: Longitudinal plan of repaired bladder in second group after one month showing hyperechoic dots (D) indicting of craniodorsal wall of the urinary bladder.

\section{Discussion}

At the first two days after the operation, animals expressed signs of pain, which might be a subsequence of the inflammatory process during maturation phase similar observation was recorded in dogs (9). Laparoscopic cystorrhaphy is considered as a perfect feasible and safest method for repairing experimental defect in dog (1). By comparison with the traditional open procedure, laparoscopic cystorrhaphy is associated with less intraoperative and postoperative complications. In dogs, a previous work used the titanium clips to closure the laparoscopic cystotomy incision results in a high efficacy and required less time to be achieved by Abass et al and Shakeri et al $(1,17)$. In addition, omentum plays an essential role in hemostasis, accelerating wound healing by neovascularize devitalized structures, and providing lymphatic drainage $(15,16)$. It has affirmed that the omentovesicopexy is a simple and efficient technique for the treatment of neurogenic dysfunctions of the urinary bladder. In this technique, the greater omentum helps in the reinnervation and revascularization of the bladder (18). In contrast to the successful using of omentum, another study utilized a human amniotic membrane, however, impairment of the urinary function has been recorded (19).

In this study the omentum was used successfully. Similar to previous studies, the present work represented that the laparoscopic surgery caused a lower incidence rate of adhesions than laparotomy $(20,21)$. Both absorbable and non-absorbable clips were successfully used and recommended for the laparoscopic surgery of bladder because are easy to be manipulated, applied and prevent hemorrhage $(22,23)$. In the first group, the radiographic images showed no leakage, the bladder appeared distended and there were distances between the titanium clips, these observations coincide with a previous work done by Boure et al (23). The positive contrast cystography was more efficient in detecting mucosal surface irregularity, bladder displacement and intraluminal structures (24). In the first group, the radiographic images showed no leakage, the bladder appeared distended and there were distances between the titanium clips, these observations coincide with a previous work done by Waseem also by Boure et al $(9,23)$. Results of the ultrasonographic examination agree with another work done by Gallatti and Masao (24) where neither thickness in the wall of urinary bladder nor leakages were noticed. Thus, this work recommends the usefulness of ultrasonography to determine the bladder wall thickening and leakage. A previous work declared that a high urine density in the urinary bladder is positively relating with the sonographic imaging of the bladder (25). However, it has determined that rupture of the bladder wall is difficult to be diagnosed sonographically, where only free abdominal fluid and thickening of the bladder wall might be recognized. A protocol of sonography, catheterization of the bladder accompanied by the injection of the saline solution might be useful for diagnosis rupture (26). Nevertheless, diagnosis of the ruptured urinary bladder still one of the challenges of ultrasonography (27).

\section{Conclusion}

We concluded that the hand-assisted laparoscopic cystorrhaphy strengthened by omentum is a practical, time saving and mini-invasive surgical technique. The using of titanium is effective for preventing both leakages and adhesion, but it is expensive.

\section{References}

1. Abass BT, Karomi WH, Ali OJ. Cystotomy in dogs by laparoscopic and laparoscopic-assisted techniques. Basrah J Vet Res. 2018;17(2):70-79.

2. Jamie RB. Managing traumatic urinary tract injuries in small animals. ACVS Symposium equine and small animals proceeding; 2001. 125$122 \mathrm{p}$.

3. Tanko MS, Awasum CA, Hassan AZ, Usman B, Johan BM. Traumatic injuries in small animals. J Vet Med Anim Health. 2014;7(1):27-32

4. Fossum TW, Hedlund CS, Hulls DA, Johanson AL, Sem HB, Willard MD, Carrol GL. Small animal surgery. $2^{\text {nd }}$ ed. St. Louis: Mosby Book; 2002. 233-240 p.

5. Cory BP, Eric M, Michael RR. Laparoscopic-assisted cystotomy for urolith removal in dogs and cats - 23 cases. Can Vet J. 2013;54(1):3641.

6. Emrah HL, Okumus Z, Dogan E. Laparoscopic surgery in veterinary medicine. Vet Res. 2007;1(1):23-39.

7. Tango EA, Mcainich JW. General urology. $17^{\text {th }}$ ed. USA: McGraw Hill; 2008. 78 p.

8. Rawlings CA, Mahaffey MB, Baranti JA, Canali SC. Use of laparoscopic-assisted cystoscopy for removal of urinary calculi in dogs. J Am Vet Med Assoc. 2003;222(6):737-759.

DOI: $10.2460 /$ javma.2003.222.759 
9. Waseem H. Study of different methods for urinary bladder closure by assisted laparoscopy [MSc Thesis]. Mosul: Collage of Veterinary Medicine, Mosul University; 2006.25-27.

10. Alkattan LM, Alkassab AM. A comparative radiological study of experimental bone and soft tissue defect healing treated with great omentum in dogs. Iraq J Vet Sci. 2009;23(1):175-179.

11. Alkattan LM, Mohammad FM, Bader OA. Gastrrohaphy with jejunum pedicle in dogs. Proceeding $14^{\text {th }}$ Assuit University Congress; 2011. 463-474 p.

12. Saltz R, Stowers R, Smith M, Gadacz TR. Laparoscopically harvested omental free flap to cover a large soft tissue defect. Ann Surg. 1993;217(5):542-6.

13. Green S, Thurmon JC. Xylazine a review of its pharmacology and use in vet medicine. J Vet Pharmacol Ther. 1988;11:295-313.

14. Albadrany MS, Mustafa NG, Alanazy MM. The effects of carbon dioxide pneumoperitoneum on certain enzyme levels in dogs. J Anim Vet Advances. 2009;8(5):946-94.

15. Ross WE, Pardo A. Evaluation of an omental pedicle extension technique in the dog. Vet Surg. 1993;22:37-43.

16. Dalela D, Gtupt AA, Singh KM. Omental wrap around the renal pedicle: An adjunctive step to minimize morbidity and recurrence after lymphorenal disconnection for chyluria. Brit $\mathrm{J}$ Urol Int. 2004;94:673-4.

17. Shakeri S, Masoudi P, Yazdani M. Cystotomy in dogs by laparoscopic and laparoscopic-assisted techniques. The $3^{\text {rd }}$ World Congress of Laparoscopic Surgeon and Gynecologists, Cyber City, Gurgaon, NCR, Delhi, India; 2012. 14-15 p.
18. Mokhort VA, Makarov VN. Omentovesicopexy with transposition of the bladder into the abdominal cavity in the treatment of neurogenic bladder. Urol Nefrol. 1990;4:20-4.

19. Shakeri S, Masoudi P, Yazdani M, Monabbati A, Mehrabani D, Tanideh N. Evaluation of human amniotic membrane as a substitute for transitional epithelium of bladder in dog. J Appl Anim Res. 2008;33:55-59.

20. Alkhilan AN, Eesa MJ, Saleh SL, Ajeel AA. A comparative study between laparoscopic complete and subtotal cholecystectomy in goats. Al-Anbar J Vet Sci. 2011;4:59-68.

21. Bonnie GC. The amazing omentum: Healing properties and surgical applications. American Association of Feline Practitioners Conference. Seattle: Washington; 2012.

22. Ou CS, Rowbotha MR. Five-year follow-up of laparoscopic bladder neck suspension using synthetic mesh and surgical staple. J Laparoendosc Adv Surg Tech A. 1999;9:249-252.

23. Boure LP, Ken CL, Peace SG, John R. Laparoscopic suture pattern for repair experimentally rupture of urinary bladder in normal neonatal calves. Vet Surg. 2005;34(1):47-54.

24. Gallatti L, Masao I. Comparison of ultrasonography and positive contrast cystography for detection of urinary bladder disorders in dogs. Braz J Vet Res Anim Sci. 2004;41(1):40-46.

25. Sing HP, Chawla SK, Chander S, Behl SM, Chandilia RK, Taya LR. Obstructive Urolithiasis in Canine- Ultrasonographic and Radiographic Observations. Inter J Mol Vet Res. 2013;3:9-12.

26. Mannion P. Diagnostic ultrasound in small animal practice. USA: Black Well; 2006. 128 p.

27. Penninck D. Bladder disorders: an Ultrasonographic Approach. European Veterinary Conference Voorjaarsdagen; 2009:^ץ_r $r \wedge$ 